superintend, we meant, not that they sanctioned individual appointments, but that they sanctioned the general system. They are the recognised heads of the department, and they sanction ererything against which they do not protest, or which they do not strive to change. Again, by "their routine duties as clerks or stewards," we did not mean to imply any absence of officials called by those titles, but to direct attention to the oppression of superintendents by an overwhelming weight of non-medical duty.-Ev. L.

\section{PROFESSOR LISTER AND THE GLASGOW INFIRMARY.}

To the Editor of THE LANCET.

SIR,-The attention of the Directors of this institution having been called to two papers, by Professor Lister, inserted on the 1st and 8th instant, "on the Effects of the Antiseptic treatment," I am instructed by them to submit the following statement in reply to his remarks, so far as relate to the alleged unhealthiness and condition of this hospital, which are unfair and not supported by facts.

He states that the wards in the surgical house were, by his antiseptic treatment, "converted from some of the most unhealthy in the kingdom into models of healthiness." With reference to this, it may be observed that, according to the statistics given in Sir James Simpson's pamphlet, "Hospitalism," part ii., the average percentage mortality of six of the largest hospitals in Great Britain from amputations for injury is $47 \cdot 28$. The mortality in Glasgow Infirmary is $43 \cdot 6$; in the Edinburgh Hospital, with which Professor Lister is now connected, it is 513. In amputations for disease, the same authority gives a like average for the same hospitals of $30^{\circ} 70$. The mortality in Glasgow is $33 \cdot 8$, and in Edinburgh, $35 \cdot 6$.

Our surgical hospital was opened in 1861, and I subjoin the number of cases treated each year, and the number of deaths, which the Directors believe will compare favourably with any similar hospital in the kingdom.

\begin{tabular}{|c|c|c|c|c|c|c|}
\hline Cear. & & Cases. & & Deaths. & & er c \\
\hline 1862 & & 1507 & & 127 & & $8 \cdot 4$ \\
\hline 363 & & 1905 & & 136 & & \\
\hline 1864 & & 2078 & & 166 & & 8. \\
\hline 186 & & 206 & & 148 & & $7 \cdot 1$ \\
\hline 186 & & 217 & & 181 & & \\
\hline & & 201 & & 132 & & 6 \\
\hline & & 221 & & 130 & & $5 \cdot 88$ \\
\hline 786 & & 216 & & 150 & & $6 \cdot 9$ \\
\hline
\end{tabular}

Professor Lister further affirms that he was engaged in a " perpetual contest with the managing body, who were disposed to introduce additional beds beyond those contemplated in the original construction," and that it is fairly attributable to "the firmness of his resistance in this matter" that these additions were not introduced. This statement the Directors positively deny. The surgical hospital contains eight wards, each sixty feet long, twenty-eight feet wide, and fourteen feet high. It was constructed to contain 200 patients, but was only at first fitted up to receive 168 . In 1866, the managers requested their medical committee (who, by their desire, had, in the previous year, gone over the fever house and assigned the number of beds to each ward), carefully to examine the medical and surgical wards, and state how many patients, in their opinion, could properly be accommodated in each. On March 16, 1866, the number was fixed at 144 for the surgical house, since which time neither adult nor child has been introduced in excess of this number. The only "contest" which the managers ever had with Professor Lister, was frequently calling his attention to the number of cases which he had kept for an unusually long time in his wards, one-third of the cases under his charge having been in the hospital for a period averaging about 180 days; and although the practice is for each surgeon to receive patients on successive days, in rotation, he had more protracted cases than the other three surgeons combined. He quotes the statisties of ward 24. The records of the hospital show that from Ist January, 1867, to 31st October, 1S69, when he left Glasgow, only 351 patients were treated by him in that ward, against 522 in the opposite ward (23) of the same size, or as nearls as possible trothirds of the number received by hiscolleagne.

Professor Lister states that he felt it "a questionable privilege to be connected with the institution." This is not very consistent with the application which he made after his period of service terminated, that he might be allowed to take charge of chronic cases without any remuneration.

$\mathrm{He}$ is also in error when he speaks of the male wards as being on a level with the ground behind the hospital, the fact being that the ground is twelve to fifteen feet below the floor of the lowest wards.

With reference to the cleaning of the wards which Mr. Lister had charge of, the same cleansing was applied to them as to all the other wards in the house.

He has fallen into a grievous mistake as to the pitburying which he saw in St. Mary's ground. The pit in question was situated about sixty jards to the north-east of the hospital. Such interments were not made there till January, 1869, and they were stopped in October last whenever discovered by the Directors. How they could affect the healthiness of the hospital for years before they were commenced one is a little at a loss to conceive.

The Directors have no intention of discussing "the effects of the antiseptic treatment"; but in their opinion, which is shared by those of their number belonging to the medical profession, the improved health and satisfactory condition of the hospital, which has been as marked in the medical as in the surgical department, is mainly attributable to the better ventilation, the improved dietary, and the excellent nursing to which the Directors have given so much attention of late years.

The medical treatment has always been satisfactory to the Directors, and they at all times have been ready to receive from their medical officers any suggestions as to how the hospital could be improved, and these have never failed to receive their immediate attention.

I am, Sir, your obedient servant,

Henry Lamond, Secretary.

Royal Infirmary, Glasgow, Jan. 18th, 1870.

\section{RELAPSING FEVER IN INDIA.}

\section{To the Editor of The LanceT.}

SIR,-A copy of the Report on "The Sanitary Administration of the Punjab," for the year 1868, by Dr. De Renzy, Sanitary Commissioner of that Province, has just come under my notice.

I quite agree with the Lieut.-Governor of the Punjab, "that this is a most valuable and interesting report;" it is a repertory of facts carefully observed, and suggestions to remedy the evils pointed out, of the most sober and practical kind, so put as to commend them to the good sense of those whose duty it is to act on them. What Dr. De Renzy has written on the all-important subject of water-supply is one of the most valuable contributions ever made to the cause of hygiene in India.

I regret, however, that in this report Dr. De Renzy has, very unintentionally no doubt, done some injustice to me. At p. 53 of the report I find the following statement.

"In the latest standard work on remittent fever (I allude to an article by Professor Maclean in 'Reynolds's System of Medicine'), some cases are described as examples 'of adynamic remittent fever' which I venture to think, and in this opinion Dr. Gray agrees with me, were in reality cases of relapsing fever. The following extract from that article describes many of the symptoms that characterised the fever of the muleteers. 'I (Dr. Haclean) was very familiar with cases of this kind when serving in the immediate vicinity of Hsderabad in the Decean. From the malarious quarters of that densel $r$ populated and most unsanitary city I used to receire into the Residency hospital, during the autumnal months, a number of cases of this kind, presenting from the first signs of creat depression; the fever after the second or third exacerbation becoming almost continued; the skin being pellowish and covered with petechiæ; the pulse exceeding 120 , small and compres. sible; the tongue dry and black; the teeth covered with 
sordes; and a disposition to hæmorrhage from nose, mouth, and bowels; and almost invariably delirium, with a tendency to coma.'

"In one of Dr. Maclean's cases, 'the symptoms,' he says, - came nearer in their ensemble to those of true yellow fever thas any he had ever seen in the whole range of our experience in the East.' Now the relapsing fever of the Punjab jails has over and over again been thought to resemble yellow fever."

I have to observe on the above-

1st. That I studied my profession in Edinburgh; that I was a pupil of Professor Alison's; that relapsing fever being a disease with which that great teacher of practical medicine was well acquainted, I was, when I went to India, much more familiar with its phenomena than with any form of malarial fevers.

2nd. That the cases I described were not cases of relapsing fever at all. They, one and all, as I have described, had distinct remissions and exacerbations; there was no cessation of symptoms on the fifth or seventh day; no apyretic interval for many days; no sudden relapse, with a return of the symptoms.

3rd. My cases responded to the free use of quinine, - a therapeutic test of itself enough to settle the question; for this remedy, so valuable, so indispensable in malarial fevers, has no power at all over genuine relapsing fever.

$4 \mathrm{th}$. In the class of cases described by me in the passage quoted, the rate of mortality is high, unless seen early, and treated with energy by quinine. The reverse is notoriously the fact in true relapsing fever, in which the death-rate, as in London at this moment, is much smaller.

Anyone reading the second paragraph of the quotation from my article would, as a matter of course, suppose that the passage quoted had reference to the Hyderabad cases; but if your readers will refer to the article, they will see at a glance that this is not the case. In fact, the passage beginning, " the symptoms came nearer, in their ensemble, to those of true yellow fever," refers to the case of Capt. B-, an officer of the Forest Conservancy Department, who was under the care of Dr. Cornish and myself. Now this gentleman was treated in Madras, where he had come direct from a great jungle; and his case was given by me as a typical one of remittent fever of the severest form, presenting some resemblance to true yellow fever in some of its symptoms. In this case, as in the others, there was no apyretic interval of days, no relapse at all, and Capt. B-owed his life to quinine.

Dr. De Renzy adds: "It is of great practical importance that errors of this kind should be removed from the textbooks on Indian disease." I submit that in this instance the "errors" cannot be laid at my door. I am, Sir, yours faithfully,

Rosal Victoria Hospital, Netley, Jan. 21st, 1870. WT. C. MACLEAN.

\section{PROFESSOR SYME AND THE EDINBURGH COLLEGE OF PHYSICIANS.}

To the Editor of The LANCET.

Sir,-I beg you will insert the enclosed letters.

$$
\text { Mr. Syme to Dr. Haldane. }
$$

January 15 th, 1870 .

My dear Sir,-Verv unwilling to make erroneous statements, especially with regard to a body so respectable as the College of Physicians, I beg you will have the goodness to acquaint me with the "erroneous statements" to which you refer, that I may take the earliest opportunity of correcting them. Yours very truly,

$$
\text { (Signed) James Syme. }
$$

\section{Dr. Haldane to Mr. Syme.}

Physicians' Hall, Jan. 15th, 1870.

My dear Sir,-As my note to the Editor of The LANCET was written by the direction, indeed, I may say to the dictation, of the Council of this College, I cannot reply to yours of this morning without laying it before the Council.

James Syme, Esq. I am, yours very truly,

A week having elapsed since the date of Dr. Haldane's Physicians, it may be concluded, as, indeed, I knew very well, that they have nothing whatever to say in support of their allegation that my statements regarding them were altogether erroneous. How far they have improved their position by this inconsiderate course, I leave the readers of IHE LANCET to determine; but, for my own part, I must beg to say that I think they would have done more wisely by accepting my statements in a complimentary sense, since nowadays there is nothing deemed more creditable than an increase of income; and that the College has established no ordinary claim to this merit can hardly be denied by anzone who, recollecting the impoverishment of former days, has visited their present magnificent hall, or partaken of their splendid hospitality. The College may well say with Vespasian, "Non olet." I am, \&c.,

Edinburgh, Jan. 22nd, 1870.

JAMES SYME.

\section{LIVERPOOL.}

(FROM OUR OWN CORRESPONDENT.)

THE sad accident which occurred last Sunday evening at St. Joseph's Roman Catholic chapel in this town, by which fifteen persons lost their lives, has of course excited much attention. It is not necessary here to enter into the circumstances which brought about this great luss of life. They have been fully related in the pages of your contemporaries, and were of a similar nature to those which have led to like accidents before. A number of people crowded together in one building, a false alarm of fire, a panic, a rush, and at the point of exit two frantic streams of people meeting, the weaker overborne, and in fifteen minutes fifteen of their number crushed to death. Such are the broad facts. It may interest you readers to know what was the appearance of the dead, and what were the symptoms in those injured only.

To speak first of the dead. No outward signs of violence were found upon them; a perfectly pallid appearance when lifted from the steps within five minutes of the occurrence; no froth or blood issuing from mouth or nostrils; no fractured ribs to be detected. Three or four breathed a few gasps after being lifted. With the exception of one woman, whose face was suffused and discoloured, all the bodies presented a calm and placid appearance. Unfortunately, as far as I can learn, no post-mortem examination has been made; and, therefore, if internal injuries sufficient to account for immediate death exist, they are not known. There were three children, aged eleven, twelve, and seven respectively, five men, and seven women. 'Two of the men were above seventy years of age.

Of the five injured, and removed to the Northern Hospital, the symptoms presented were, insensibility, with throwing of the arms about, and fits of excitement; no peculiarity in the pulse-a state resembling (according to one of the resident surgeons of the hospital) what he had often met with in patients suffering from concussion of the brain. There were no bruises observed. The insensibility lasted in the most severe case between four or five hours, but was never complete, the patient being easily aroused. In another case the excited state of the brain for two days was extreme. These cases have nearly quite recovered. They have no recollection of the struggle.

The inquest is not yet concluded, but there is one point upon which all those who witnessed the accident seem agreed, and that is the very few minutes-not certainly fifteen-which elapsed from the commencement of the rush to the time when the dead were removed.

Iiverpool, Jan. 26th, 1870.

\section{(1) bituanty.}

\section{MR. THOMAS G. WALES}

(OF DOWNHAM MARKET).

$H_{A D}$ a stranger entered this town about two o'clock on Tuesday afternoon, and, walking through its streets, asked "For whom tolls the passing-bell?-on whose account has the place assumed the garb of sorrow ?"-he would have been told "The town has lost one of its worthiest sons. We mourn because to-day are carried to the grave the mortal remains 